\title{
Adolescence: a time of risk taking
}

\section{A J Robinson, K Rogstad}

\section{Adolescent sexual health must remain a top priority globally}

T o have the first themed issue for Sexually Transmitted Infections as adolescent sexual health is fortuitous. The United Kingdom has the unenviable position of being top of the league tables for teenage pregnancy in western Europe with 9 in 1000 girls aged 13-15 and 63 in 1000 girls aged 16-19 becoming pregnant. ${ }^{1}$ Although there has been a resurgence of sexually transmitted infections (STIs) diagnosed across all age groups tested in genitourinary medicine (GUM) clinics, ${ }^{2}$ the greatest rise in prevalence rates has been seen with chlamydial and gonococcal infections in young men and women, especially teenagers.

Concern about sexual health of adolescents is not confined to the United Kingdom. As can be seen from the published papers in this issue of the journal, the problem is global. The majority of young people live in developing countries where the burden of STIs and HIV is greatest. ${ }^{3}$ Unicef has emphasised the importance of preventative strategies targeting young people if the HIV epidemic is to be stemmed. ${ }^{4}$ European countries that have been more successful in reducing teenage pregnancy and STI prevalence rates than the United Kingdom have over the past 10 years seen a resurgence of these. ${ }^{5}$ Even in Sweden, which has previously had low prevalence rates of STIs and teenage pregnancy, an increase in termination of pregnancy and STI rates has been reported. ${ }^{6}$

Adolescence is a time of risk taking as part of the process of growing up. Age at first intercourse in the United Kingdom has been falling, with a median reported age at first intercourse of 16 in girls and boys. $^{7}$ Young people are more likely to have concurrent relationships, monogamous relationships of short duration and higher frequency of acquisition of new partners. ${ }^{8}$ All of these factors favour increased transmission of STIs. There may be increased susceptibility of younger women to infection and sequelae through physiological influences such as cervical ectopy. Some youngsters are more vulnerable, particularly "looked after" children and those previously abused, which brings other allied emotional and social difficulties. ${ }^{10}$ Young people report having more risky sex under the influence of alcohol but the nature of the association is complex, as highlighted in the recent report by Alcohol Concern. ${ }^{11}$ For both sexes, regret at having first intercourse too early is associated with being drunk or "stoned."12 Recreational drugs have been studied extensively as factors in HIV risk behaviour in homosexual men but little research has looked at drug use and acquisition of STIs. Crosby et al have shown that marijuana use is a strong predictor of Trichomonas vaginalis infection in young African-American women. ${ }^{13}$

Chlamydia trachomatis is the commonest infection that affects adolescents. Effective screening of this young age group poses a challenge. Efforts to implement screening must also address healthcare providers' attitudes and perceptions as to its value, cost effectiveness, and simplicity of testing methods. ${ }^{14}$ There must be sufficient resource to provide outreach services and nucleic acid amplification tests for noninvasive sampling techniques. Sadly, in the United Kingdom, despite knowing that high prevalence rates exist, a national chlamydia screening programme is just being rolled out and in the first instance will include only 10 centres. ${ }^{15}$ Other countries have already instigated screening programmes and in the United States post-treatment rescreening has been suggested in the latest guidelines. ${ }^{16}$ Reinfection has been associated with young age, ${ }^{17-21}$ although there is evidence that many adolescents temporarily change their behaviour following diagnosis with an STI by abstaining or using condoms. ${ }^{22}$ In this age group consideration should be given to rescreening and novel ways of managing partners.

The legal framework, including the age of consent for sexual intercourse and offering treatment services to young adolescents, varies between countries. Young people rate confidentiality as a high priority when attending services. In the United Kingdom colleagues providing sexually transmitted infection or HIV services are anxious about legal aspects when caring for under 16s. Clinicians in England are left with the difficulty of balancing the rights of the young person to confidentiality and treatment, as defined by the Fraser ruling, ${ }^{23}$ with child protection issues associated with the Children Act $1989^{24}$ and the European
Convention of Human Rights, where no "case law" related to these complex issues yet exists. Guidelines for setting up of "Young Persons Services" previously published highlight the problems. ${ }^{25}$ The national guidelines for the management of suspected sexually transmitted infections in children and young people ${ }^{26}$ published in this issue of the journal ( $p$ 324) are extensive and provide a framework for good practice in relation to confidentiality and consent. The importance of acting in the best interests of the child and ensuring discussion with the multidisciplinary team is essential when making difficult decisions about the management of a young person below the age of consent. The guidelines also cover aspects of the management of children who may have a sexually transmitted infection including diagnosis/treatment of STIs and signs of sexual abuse. The appendices include proformas that can be used to improve the quality of history taking in respect of assessing possible abuse, and for processing samples which require a chain of evidence. The issue of chain of evidence and retention of specimens is uncertain and is currently being assessed by key stakeholders; when a consensus is reached the guidelines will be amended accordingly.

For adolescents, greater effort is needed in service provision, health promotion, and research to identify the interventions that are most likely to succeed. This requires close collaboration between health services, education, and sociobehavioural initiatives. When adolescents are asked where they wish to get information about sex, parents come high on the list. ${ }^{27}$

Dr Robbie Morton's obituary is in this issue. He was a great proponent of having accessible services for young people with friendly, approachable staff. He always maintained that sex education should be given to parents alongside any initiatives for adolescents. With some evidence suggesting that ease of family discussion about sex has an effect on the likelihood of teenage pregnancy, ${ }^{29}$ and that promotion of parent-child communication may impact on sexual behaviour, ${ }^{30}$ we need to ensure that sufficient heed is paid to parents' sex education. The Teenage Pregnancy Strategy ${ }^{31}$ highlighted that parents are given little help in talking to their children about sex but, even in 2001,39\% of young people said they had been given no information about sex by their parents. ${ }^{32}$ Adolescent sexual health must remain a top priority globally if any impact is to be made on unwanted pregnancies and the rising prevalence of HIV and sexually transmitted infections.

Sex Transm Infect 2002;78:314-315 


\section{Authors' affiliations}

A J Robinson, Department of GU Medicine Mortimer Market Centre, London WCIE 6AU UK

K Rogstad, Department of GU Medicine, Royal Hallamshire Hospital, Glossop Road, Sheffield S10 2JF, UK

Correspondence to: Dr Angela Robinson; arobinson@gum.ucl.ac.uk

\section{REFERENCES}

1 PHLS, DHSS \& PS and the Scottish ISD D 5 Collaborative Group. Sexually transmitted infections in the UK: new episodes seen at genitourinary medicine clinics, 1995 to 2000 London: Public Health Laboratory Service, 2001.

2 Diuretic T, Catchpole M, Nicoll A, et al. Genitourinary medicine services in the United Kingdom are failing to meet current demand. Int J STD AIDS 2001;12:571-2.

3 Aggleton RK. Adolescent sexuality. UNAIDS BP Digest Document 1999:1-4

4 UNICEF/UNAIDS/WHO. Young people and HIV/AIDS :opportunity in crisis. Geneva: UNAIDS, June 2002

5 Nicoll A, Hamers FF. Are trends in HIV gonorrhoea, and syphilis worsening in western Europe? BMV 2002;324:1324-7.

6 Edgardh K. Adolescent sexual health in Sweden. Sex Transm Infect 2002;78:352-6.

7 Wellings K, Nanchahal K, Macdowall W, et al. Sexual behaviour in Britain: early heterosexual experience. Lancet 2001;358: 1843-50

8 Johnson AM, Mercer C, Erens B, et al. Sexual behaviour in Britain: partnerships, practices, and HIV risk behaviours. Lance 2001;358:1835-41.

9 Westrom L, Mardh P. Acute pelvic inflammatory disease. In: Holmes KK, Sparling PF, Mardh P, et al, eds. Sexually transmitted diseases. 3rd ed. New York: McGraw-Hill, 1999.
10 Anfield A, Kawsar MR, Walters E, et al. Prevalence of mental health and social difficulties as reported by female child and adolescent survivors of rape and sexual assault attending a specialist clinic. Sex Transm Infect 2002; 78: (in press).

11 Alcohol Concern. Alcohol and teenage pregnancy 2002. London: Alcohol Concern, http://www.alcoholconcern.org.uk

12 Wight D, Henderson M, Raab G, et al. Extent of regretted sexual intercourse among young teenagers in Scotland: a cross sectional survey. BM 2000-320:1243-4.

13 Crosby R, DiClemente RJ, Wingood GM, et al. Predictors of infection with Trichomonas vaginalis: a prospective study of low income African-American adolescent females. Sex Transm Infect 2002;78:360-4.

14 Boekeloo BO, Snyder MH, Bobbin M, et al. Provider willingness to screen all sexually active adolescents for chlamydia. Sex Transm Infect 2002;78:369-73.

15 Department of Health. The national srategy for sexual health and HIV. Implementation Action Plan. London: DoH, 2002. http://www.doh.gov.uk/

16 Centers for Disease Control and Prevention. Sexually transmitted diseases 2002. MMWR 2002:51 (No RR-6)

17 Burstein GR, Zenilman JM, Gaydos CA, et al. Predictors of repeat Chlamydia trachomatis infections diagnosed by DNA amplification testing among inner city females. Sex Transm Dis 2001;77:26-32.

18 Orr DP, Johnston K, Brizendine $E$, et al. Subsequent sexually transmitted infection in urban adolescents and young adults. Arch Pediatr Adolesc Med 2001;155:947-53.

19 Xu F, Schillinger JA, Markowitz LE, et al. Repeat Chlamydia trachomatis infection in women: analysis through a surveillance case registry in Washington State, 1993-1998. Am J Epidemiol 2000;152:1 164-70.

20 Richey CM, Maccuso M, Hook E. Determinants of reinfection with Chlamydia trachomatis. Sex Transm Dis 1999;26:4-1 1.

21 Hughes G, Brady A, Catchpole MA, et al. Characteristics of those who repeatedly

\section{Adolescent reproductive health interventions}

\section{F M Cowan}

Must be a priority if the next generation is not to be decimated by HIV

$\mathrm{T}$ he broad aim of adolescent reproductive health interventions (ARHI) is both to reduce the adverse consequences of sexual behaviour and to improve the quality of sexual relationships for young people, both as young people today and also in their future life as adults. This article aims to describe the different approaches that have been employed and to review the methodological issues that face both those developing and implementing these interventions and the researchers trying to evaluate their effectiveness. It makes no attempt to systematically review all the relevant literature.

\section{BACKGROUND}

Young people are particularly vulnerable to the adverse consequences of early sexual behaviour ${ }^{1}$ and as such are widely recognised to be one of the most important groups for reproductive health interventions. ${ }^{2}$ This increased vulnerability is caused by a number of biological, behavioural, and psychological factors including hormonal changes at puberty, cervical anatomy, immunological naivety, inability to recognise symptoms of infection, sexual experimentation including experimentation with same sex partners, non-consensual sex, imperception of risk, immaturity of communication skills, contraception choice, poor acquire sexually transmitted infections: a retrospective cohort study of attendees at three urban sexually transmitted disease clinics in England. Sex Transm Dis 2001;28:379-86.

22 Fortenberry JD, Brizendine EJ, Katz BP, et al. Post-treatment sexual and prevention behaviours of adolescents with sexually transmitted infections. Sex Transm Infect 2002;78:365-8

23 Gillick v West Norfolk and Wisbech AHA [1986] AC 112, [1985] 3 WLR 830, [1985] 3 All ER 402, HL

24 HMSO. The Children Act 1989. London: Stationery Office.

25 Rogstad KE, Ahmed-Jushuf IH, Robinson AJ Standards for comprehensive sexual health services for young people under 25 years. Int J STD AIDS 2002;13:420-4.

26 Thomas A, Forster G, Robinson A, et al National guideline for the management of suspected sexually transmitted infections in children and young people. Sex Transm Infect 2002;78:324-31.

27 Balding J. Young people in 1999. Exeter Health Education Unit. Exeter: University of Exeter, 2000

28 National Children's Bureau Talkshop Consultations.

29 Wellings K, Wadsworth J, Johnson A, et al. Teenage sexuality, fertility and life chances. Report prepared for the Department of Health. London: $\mathrm{DoH}, 1996$.

30 Blake S, Simkin L, Ledsky R, et al. Effects of a parent-child communications intervention on young adolescents' risk for early onset of sexual intercourse. Family Planning Perspectives 2001;33:52-61.

31 Social Exclusion Unit. Teenage pregnancy. London: Stationery Office, 1999:35-41.

32 Teenage Pregnancy Strategy Evaluation Team Tracking Survey. Report of results of benchmark wave. London: Teenage Pregnancy Unit, 2001.

health seeking behaviour, and alcohol or illicit substance use. In addition, structural (societal) factors that facilitate HIV and STI spread are also well documented. ${ }^{4}$ Economic deprivation, sex inequalities and mobility, including social disruption, are all important determinants of HIV /STI spread.

The consequences of sexually transmitted infection (STI) and unplanned pregnancy can be devastating. Young women are at the start of their reproductive life and risk compromising their future fertility through tubal occlusion or ectopic pregnancy. In many areas, young women who get pregnant are withdrawn from school, further disadvantaging them. In countries where access to abortion is limited, the gynaecological consequences of "back street" abortion can be dire. While young men suffer fewer direct health consequences of early sex, infection or pregnancy can still have adverse consequences for them-for example, with respect to further education and training opportunities.

Numerically, young people between the ages of 10 and 24 make up one third of the world's population. Eighty per cent of these young people live in developing countries where the burden of infection 
with both STIs and HIV is greatest. ${ }^{5}$ Half of all people infected with HIV globally are infected before age $25 .{ }^{6}$

Developing, implementing, and evaluating interventions that not only minimise the risk of sexual intercourse in young people but also facilitate development of healthy sexual behaviour patterns and relationships are therefore a priority. There is evidence that initiating prevention interventions when teenagers are still sexually naive, before patterns of risky sexual behaviour are firmly established, is likely to be more effective than trying to change established behaviour in older adults. ${ }^{7}$ Interventions started in early adolescence will therefore have the greatest chance of minimising the risk from early sexual intercourse.

However, adult discomfort with adolescent sexuality is common and there is concern among some, often highly influential groups, that sex education promotes experimentation and increases sexual activity. ${ }^{8}$ There is disagreement about how explicit educational material should be, how much there should be, how often it should be given, and when it should be initiated. ${ }^{9}$ Given the importance of this topic there has been relatively little rigorous evaluation of the effectiveness and cost effectiveness of reproductive health interventions targeting adolescents, ${ }^{90}$ which means that policy makers with concerns about public reaction have few data to support widespread and comprehensive implementation.

\section{ADOLESCENT REPRODUCTIVE HEALTH INTERVENTIONS}

Adolescent interventions can be broadly divided into behavioural interventions, which seek to change the knowledge, skills and attitudes of individuals and structural interventions, which aim to tackle broader societal issues that drive the spread of STIs. The two approaches are not mutually exclusive and it is likely, for example, that individual behaviour change will best be sustained within a community that is broadly supportive of those behaviours. In addition, the broader cultural perspective of the community will greatly influence the feasibility of delivering an intervention within that community and will also affect how the recipients respond to it. ${ }^{11}$

\section{BEHAVIOURAL INTERVENTIONS}

The aim of behavioural interventions is to influence individual behaviour patterns by improving control over sexual activity, delaying initiation of intercourse, minimising partner change, promoting appropriate health seeking behaviour, and encouraging use of contraception or in the case of young homosexual men, non-contraceptive barrier methods.

Models of sex education fall broadly into those that advocate abstinence from sex, usually until marriage, and those that teach more broadly about sexuality. In the abstinence programmes contraception and condom use are not discussed whereas the sexuality programmes teach both about abstinence and how to have safer sex if abstinence is not an option. Abstinence programmes appeal to adults who believe that knowledge of how to have sex safely will lead to experimentation.

Several reviews have sought to examine the impact of different approaches to sexual health education for young people. ${ }^{9}{ }^{101213}$ All reviews agree that the methodological quality of most of the included studies limits the usefulness of their findings. Despite this, a consistent finding across the various studies from around the world is that there is little support for the view that sex education (either abstinence or sexuality based) encourages sexual experimentation or increased sexual activity.

\section{Intervention content and delivery}

Although traditional knowledge based approaches to sex education have been shown to change knowledge, they have little impact on behaviour. ${ }^{14}$ The behavioural interventions that appear most likely to result in behaviour change are those that are theoretically based and draw on social psychological theories of behaviour change, derived from research that seeks to understand the origins and control of sexual behaviour. ${ }^{15}$ Sociological research into young people's sexuality suggests that sexuality is learnt, learnt differently by males and females, and is heavily influenced by genderpower relationships (which are culturally as well as individually determined). ${ }^{.15}$ In addition, perception of health risk varies between individuals and is also culturally determined. ${ }^{16}$

Other factors that are likely to be important are that the behavioural aims of the curriculum are clearly defined and closely focused on sexual risk reduction. ${ }^{7}$ Particularly important is that behaviours should be modelled ${ }^{7}$ and that young people should get a chance to develop and rehearse strategies for practising safer sexual behaviour and in so doing increase their self efficacy. ${ }^{17}$ As cultural perception of sex, power, and risk are important in shaping an individual's sexuality, and therefore the outcome of their sexual encounters, programmes should provide young people with the opportunity to reflect on their cultural and personal assumptions about these issues, ideally before they become sexually active. Although many interventions have been developed for use in young people, relatively few have been theoretically based. ${ }^{18}$

\section{Context of intervention delivery}

Interventions targeting adolescents can be based in school or within the wider community. While school based education is attractive in that it is potentially cost effective and feasible, in many communities it will be the out of school youth who are most vulnerable to sexual risk taking for a variety of reasons. As school based sex education has to compete with academic subjects for resources and time within the main curriculum, programmes are often poorly implemented. Successful implementation requires genuine political support from within government, it needs to be properly timetabled, and its implementation needs to be monitored in the same way as it is for other subjects.

School based programmes can be delivered by teachers or by peer educators or a combination of both. Several studies have demonstrated that teachers need training, in order to deliver sex education effectively. Untrained teachers report discomfort with the materials, the message, and the interactive mode of delivery, ${ }^{7}$ and there are moves in many countries to get training in sex education incorporated into the basic teacher training qualification. Of note, in countries with high rates of HIV infection, teachers are one of the worst affected professional groups and not only need training to teach their pupils, but also to protect themselves. ${ }^{19}$

In the context of young people, peer education refers to pupils delivering an education programme who are of similar or slightly older age than the pupils receiving the programme. Several studies have demonstrated the effectiveness of peer educators in promoting behaviour change. The use of peer education in adolescents is particularly compelling since peer pressure is a major factor motivating behaviours. ${ }^{20}$ Peer educators can act as effective role models, thereby facilitating positive changes in adolescent behaviour norms. ${ }^{21}{ }^{22}$ By using the same language as their peers they may be better able to communicate with them. However, the logistics of programme delivery and training and supporting peer educators are considerable.

Two systematic reviews have been undertaken to examine the effectiveness of peer education in young people. The first, which sought to compare the effectiveness of peer led versus adult led health education (rather than sex education), found that where trials reported a change in self reported behaviour, peer led was at least as effective as adult led education..$^{23}$ The second review looked at the impact of peer led education itself and found that only 12 out of 462 studies were methodologically sound and that of these, only seven reported an effect on behavioural outcomes. ${ }^{20}$ They identified five sound studies that compared the 
impact of peer and teacher lead delivery. Two of these studies found that peer led was more effective than teacher led, two found that it was as effective, and one study found that neither teacher nor peer led was effective.

A recent systematic review of prevention interventions undertaken in the United States suggested that education targeting single ethnic groups may be more effective than those aimed at more heterogeneous populations. ${ }^{13}$

In addition to educating young people either in or out of school, there is also interest in educating parents about issues relating to adolescent sexuality, with the aim of improving their communication with young people and helping them act as educators/advisers.

\section{STRUCTURAL INTERVENTIONS}

Structural factors associated with HIV risk and prevention have been defined as physical, social, cultural, organisational, community, economic, legal or policy aspects of environment that impede or facilitate a person's effort to avoid HIV infection. ${ }^{24}$ Traditionally, adolescent reproductive health interventions have not addressed these structural factors which impede their efforts to avoid infection/ pregnancy. ${ }^{25}$ Several workers have demonstrated that it may be unrealistic to expect individual behaviour change when the broader societal and cultural context is not supportive of this change as, for example, is often the case for interventions that promote condom use and partner reduction strategies for impoverished heterosexual women in developing countries. ${ }^{19}{ }^{26}$ However, there is a balance to be struck between what is ideal and what is feasible. It would not be reasonable to delay implementing behavioural interventions until complementary structural adjustments to the wider community can be implemented. Clearly societal factors such as economic deprivation and sex inequality are complex issues and will take time to change at a societal level.

Structural interventions can be targeted at the individual (micro level-for example, microfinance initiatives which aim to economically empower young women ${ }^{27}{ }^{28}$ ), at organisations (intermediate level-for example, by providing reproductive health services within schools or needle exchange schemes for drug users) or at environment (macro level—for example, bringing about legislative changes in age of consent for homosexual men or provision of the over the counter emergency contraception). ${ }^{24}$ In the Netherlands, mass media approaches have been successfully used to change societal attitudes and raise awareness of sexual health issues. ${ }^{29}$ As for behavioural interventions there is relatively little research evidence on what works and what doesn't, partly because it can be difficult to measure changes attributable to an intervention at a societal level. ${ }^{4}$ There is increasing interest in developing structural interventions to complement behavioural programmes. ${ }^{30}$

\section{FURTHER RESEARCH}

A common theme among literature reviews of adolescent sexual behaviour and reproductive health interventions is the poor methodological quality of much of the formative research, intervention development, and evaluation. ${ }^{79} 15202331$ This has been attributed both to lack of cooperation between health promotion practitioners and researchers in terms of developing theoretically sound interventions, ${ }^{32}$ and to the suspicion with which many social scientists, educationalists, health promotion practitioners, and policy makers regard experimental research. ${ }^{33}$ Many educationalists regard access to sex education as a right in the same way as they regard access to learning to read and are therefore not interested in whether or not it changes some specific behavioural or biomedical outcome measures in an experimental study. This view contrasts sharply with that of some parents and religious groups, who are suspicious of sex education on the basis that it promotes sexual activity. Policy makers are not sure of the relative cost effectiveness of different educational approaches with different resource implications. Possibly as a result of this uncertainty, studies from around the world show that sex education is often poorly implemented and that high rates of HIV, STI, and unplanned pregnancy among adolescents continue to occur. O'Leary et al have called for the use of guidelines for reporting (and therefore designing and conducting) STD/HIV behavioural intervention research in the hope that this would enhance the utility and interpretation of the results from the large number of studies being conducted. ${ }^{34}$

\section{Outcome measures to assess effectiveness}

With complex behavioural interventions, which aim to change skills, attitudes, peer norms and behaviours, the measures for determining impact need to reflect the aims of the intervention. In reality, measuring changes in all these areas, using scientifically robust outcome measures in well designed studies, is difficult to do. Therefore, many studies determine impact of such interventions by measuring changes in knowledge and self reported behaviour and intentions, rather than including externally valid measures such as STI rates or abortion statistics. However, sexual behaviour is difficult to measure and validate, ${ }^{35}{ }^{36}$ particularly in young people. This is of particular concern in trials of sexual behaviour interventions where reporting of the behaviour, rather than the behaviour itself, may be changed by the intervention, resulting in differential bias between the two arms of the study. ${ }^{37}$ To date there are very few published evaluations of sex education that have used biological markers to determine effectiveness and none in developing countries.

Two recently published systematic reviews that have reported on biological outcomes of effectiveness have disappointingly shown no effect on these. In the first, a review of interventions that aim to prevent unintended pregnancy among adolescents found no difference in pregnancy rates between those receiving the interventions and those who did not (odds ratio $1.04,95 \%$ CI 0.78 to 1.40). ${ }^{12}$ In addition, they found no difference in reporting of risky behaviours. In contrast, a review of US based adolescent HIV prevention interventions did find evidence of behaviour change but no difference in the rates of STIs between intervention and control arms (odds ratio $1.18,95 \%$ CI 0.48 to 2.86 ), although this may be because insufficient studies have been done to examine this. ${ }^{13}$

\section{Process evaluation}

Clearly it is important when assessing the effectiveness of behavioural or structural interventions to determine whether the intervention was delivered as intended, and if not what barriers to implementation exist and how these can be overcome. This information is crucial to determining the reasons for the success or failure of a particular project. For example, the lack of effect in the Masaka trial of a teacher led sex education curriculum was likely to be because the programme was poorly implemented owing to lack of classroom availability and because key sessions were omitted as a result of teacher discomfort. ${ }^{38}$

\section{CONCLUSIONS}

The development and effective implementation of adolescent reproductive health interventions must be a priority for many areas of the world if the next generation is not to be decimated by HIV. It is likely that interventions that combine a behavioural and structural approach will be those most likely to succeed. However, although adolescent reproductive health has been on the health and education agenda for many years, there is still considerable apathy towards implementation of intervention programmes in many countries. While this is in part because of vociferous opposition from the "moral minority" it is also because of the lack of robust evidence about what works and what does not. The recent systematic reviews 
that highlight the lack of effect of interventions on objective biological outcome measures, despite demonstrating an effect on reported behaviour, have important implications for future research design. Health promotion practitioners, teachers, and educational and health researchers need to work together to define research priorities and ensure that the most promising interventions are appropriately and rigorously evaluated using objective, well validated markers of effectiveness

Sex Transm Infect 2002;78:315-318

\section{Author's affiliations}

F M Cowan, Department of Sexually Transmitted Diseases, Royal Free and University College Medical School, London, UK ; frances@uz-ucsf.co.zw

\section{REFERENCES}

1 Cowan FM. Sexually transmitted infections in adolescents. Contemporary Reviews in Obstetrics and Gynaecology 2000:39-43.

2 UNAIDS. Report on the global HIV/AIDS epidemic: June 2000.

3 Holmes KK. Human ecology and behavior and sexually transmitted bacterial infections. Proc Natl Acad Sci 1994;91:2448-55.

4 Parker R, Easton D, Klein C. Structural barriers and facilitators in HIV prevention; a reveiw of international research. AIDS 2000;14(Suppl 1):22-32.

5 Aggleton RK. Adolescent sexuality. UNAIDS BP Digest Document 1999: 1-4. 6 UNAIDS. AIDS epidemic update, Dec 1999. UNAIDS update 1999

7 Kirby D, Short L, Collins J, et al. School based programmes to decrease sexual risk behaviours: a review of effectiveness. Public Health Report 1994;109:339-60.

8 UNAIDS. Learning and teaching about AIDS at school. UNAIDS Technical Update 1997.

9 Grunseit A. Impact of HIV and sexual health education on the sexual behaviour of young people. UNAIDS Best Practice Collection 1997:5-62.
10 Oakley A, Fullerton D, Holland S, et al. Sexual health education interventions for young people: a methodological review. BM 1995;310:158-62.

11 Lewis J,.Knijn T. A comparison of English and Dutch sex education in the classsroom. Education and Health 2001:19:59-64.

12 DiCenso A, Guyatt GH, Griffith WL. Interventions to reduce unintended pregnancies among adolescents: systematic review of randomised controlled trials. $B M$ 2002;324: 1426-30.

13 Mullen PD, Ramirez G, Strouse D, et al Meta-analysis of the effects of behavioural HIV prevention interventions on the sexual risk behaviour of sexually experienced adolescents in controlled studies in the United States. J AIDS 2002:30:S94-105.

14 King A, Wright NP. AIDS and youth: an analysis of factors inhibiting and facilitating the design of interventions. GPA/WHO 1993

15 Wight D, Abraham C, Scott S. Towards a psycho-social theoretical framework for sexual health promotion. Health Education Research 1998; 13:317-30.

16 Adams J. Risk. London: UCL Press, 1995

17 Bandura A. Self-efficacy mechanism in psychobiologic functioning. Self-efficacy: thought control of action. Washington: Hemisphere, 1992:155-89.

18 Fisher JD,. Fisher WA. Changing AIDS-risk behaviour. Psychol Bull 1992;111:455-74.

19 Heisse L,. Elias C. Transforming AIDS prevention to meet womens needs: a focus on developing countries. Soc Sci Med 1995;40:931-43.

20 Lindsey B. Peer education: a view point and critique. Journal of the American College of Health 1997:45:187-9.

21 Phelps FA,.Mellanby AR. Sex education: the effect of a peer education programme on pupils (age 13-14 years) and their peer leaders. Health Education Journal 1994;53:127-39

22 Mellanby AR, Phelps FA, Crichton NJ, et al. School sex education: an experimental programme in educational with medical benefit. BM 1995;311:414-7.

23 Harden A, Oakley A, Oliver S. Peer delivered health promotion for young people: a systematic review of different study design Health Education Journal 2001;60:339-53.

24 Sumartojo E. Structural factors in HIV prevention: concepts, examples and implications for research. AIDS 2000;14(Suppl 1):3-10.
25 Rotherham-Borus $M$. Expanding the range of interventions to reduce HIV among adolescents. AIDS 2000;14(Suppl 1):33-40.

26 Anon. HIV prevention: the need for methods that women can use. Am J Publ Health 1990;80:460-2

27 Esim S, Malhotra A, Mathur S, et al. Making it work: linking youth reproductive health and livelihoods. Washington DC: International Center for Research on Women, 2001.

28 Population Council. Adolescent girls' livelihoods: essential questions, essential tools: a report on a workshop. New York: Population Council and ICRW, 2000

29 Yzer MC, Siero FW, Buunk BP. Can public campaigns effectively change psychological determinants of safer sex? An evaluation of three Dutch campaigns. Health Education Research 2000;15:339-52.

30 Anon. Enriching the mix: incorporating structural factors into HIV prevention. AIDS 2000; 14(suppl 1):1-2.

31 Jejeebhoy S. Adolescent sexual and reproductive behaviour: a review of the evidence from India. Soc Sci Med 1998;46: 1275-90.

32 Kok G, Green L. Research to support health promotion in practice: a plea for increased cooperation. Health Promotion International 1990;5:303-7.

33 Oakley A. Experimentation and social interventions: a forgotten but important history. BM 1998:317:1239-41.

34 O'Leary A, DiClemente RJ, Aral SO Reflections on the design and reporting of STD/HIV behavioral intervention research. AIDS Education and Prevention 1997;9(suppl A): $1-14$

35 Peterman TA, Lin LS, Newman DR, et al. Does measured behaviour reflect STD risk? Sex.Trans.Dis. 2000;27:446-51.

36 Aral SO, Peterman TA. Measuring outcomes of behavioural interventions for STD/HIV prevention. Int J STD AIDS 1996;7(S2):30-8.

37 Cowan FM, Langhaug LF, Mashungupa G, et al. School based HIV prevention in Zimbabwe: feasibility and acceptability of evaluation trials using biological outcomes. AIDS 2002:(in press).

38 Kinsman J, Nakiyingi J, Kamali A, et al. Evaluation of a comprehensive school-based AIDS education programme in rural Masaka, Uganda. Health Education Research $2001 ; 16: 85-100$.

of these initiatives, though embraced by many with enthusiasm and best intent and often at great financial cost, have not been evaluated, reported, or subjected to any rigorous scientific scrutiny.

Hence the two original articles in a recent issue of the $B M J$ are particularly welcome. ${ }^{12}$ The Canadian investigators, DiCenso et al, undertook a meta-analysis of the results of 26 randomised controlled trials of published and unpublished interventions (including sex education classes, school or family planning based clinics, and other community based programmes). There was no evidence that such interventions either delayed sexual intercourse, improved the use of contraception, or reduced the incidence of unintended pregnancy in adolescents. ${ }^{1}$ The investigators from Scotland, Wight et al, published the long awaited interim report of a randomised trial comparing a specially more recent history, detailed contraceptive techniques were published by Charles Knowlton in 1832; contraceptive methods became widely available in the United Kingdom and other developed there was worldwide acceptance population explosion.

In developed countries, adolescents have been targets of pregnancy prevention strategies by communities since the late 1980s, as unintended teenage pregnancy is considered an adverse event for society and individuals. However, many 
designed, intensive sex education programme for adolescents (SHARE) with conventional sex education in schools. ${ }^{2}$ Six months after the intervention, there was no difference in sexual risk taking in the adolescents, despite an improved knowledge of sexual health. Data from this study on unintended pregnancy rates are not yet available.

These disheartening results should not come as a surprise to most of us working in the fields of sexual health. The questions that spring to mind are: Why does a young person, living in an affluent society, surrounded by the multitude of contraceptive options available to us in the 21 st century, armed with the knowledge of the adverse consequences of unsafe sex, get pregnant? What can be done about it? The answer to both is: We don't fully know.

Firstly, knowledge alone is not enough to bring about changes in behaviour. Few people are unaware of the harm of cigarette smoking, the dangers of speeding on the road, or the adverse effects of obesity. If knowledge alone were the solution, then these problems should already have disappeared, which outcome manifestly shows no likelihood of occurring any time soon.

Secondly, there are many personal, ethical, economic, and social reasons for uptake (or not) of safe sexual practices and pregnancy avoidance. Religious and ideological beliefs, biological urges, cultural and familial patterns, peer group pressure reflecting the power of modern mass media may all be more potent factors than messages of sex education in school. It is simplistic to attribute the low teenage pregnancy rate in the Netherlands to school sex education programmes alone. Their successful strategy also included mass media campaigns, open discussion on sexuality, strong desire to reduce reliance on abortion, and ongoing education. ${ }^{3}$ The response of young people to such strategies may depend on other less easily quantifiable factors such as sexual attitude and social mores. Recently studies of low income African-American adolescent females suggest high risk sex is associated with several elements in sexual dynamics such as having older boy friends, ${ }^{4}$ relationship pattern favouring male decision making, perceived invulnerability to acquiring STD, ${ }^{5}$ even positive beliefs about early parenthood. ${ }^{6}$ Hence what works for white teenagers in the Netherlands may not be applicable in the black neighbourhoods of Alabama, United States. We need large scale, longitudinal and, especially, culturally specific studies exploring the social determinants of unintended pregnancy and unsafe sexual practices in young people, to help us determine what interventions would be most effective for that particular population.

\section{Why does a young person, living in an affluent society, surrounded by the multitude of contraceptive options available to us in the $21 \mathrm{st}$ century, armed with the knowledge of the adverse consequences of unsafe sex, get pregnant?}

Thirdly, studies of factors leading to illicit drug or alcohol use in adolescents highlighted the effect of the influence of parents, peers, and behaviour of "the most admired person." (Perhaps our football heroes can contribute more to our youth than national pride alone!) In addition, lack of self confidence and communication skills increased susceptibility to drug use. ${ }^{78}$ In studies of sexual behaviour, teenage girls living in a perceived supportive family, where parents knew whom they were with, and reporting frequent communication with parents, were more likely to negotiate use of condoms and practise safe sex. ${ }^{9}{ }^{10}$ It could be argued that breakdown of the traditional family unit is the prime reason for the enormous social problem facing teenagers in Western society today. The rising pregnancy rate is a mere reflection of such social disintegration.

However, apparently insurmountable obstacles are not an excuse for nihilism. Encouragingly, there is some evidence that interventions are worth while. Teaching specific social skills to young adults at high school, coupled with at least 2 years of booster sessions, has been shown to be effective in drug misuse prevention. ${ }^{11}$ Sex education may have more impact if started even earlier than junior high school. Children in kindergarden or early primary school are more susceptible to imprinting. Perhaps parental involvement in any sex education programmes, with renewed emphasis on parental supervision, may also be crucial for their success.

Finally, it is important to point out that statistics equate teenage pregnancy with unintended or unwanted pregnancy, which may not necessarily be true, especially for certain cultural and ethnic groups. Furthermore, we may need to ask ourselves why teenage pregnancy (as distinct from acquiring sexually transmitted infections) is considered a bad thing, and for whom? There is evidence that adolescent childbearing for some is the means of adapting to, rather the cause of, urban poverty so decreasing teenage pregnancy may have less impact on the socioeconomic wellbeing of the young family unit concerned. ${ }^{12}$ The observed health related disadvantage of children born to teenage mothers may not be the result of maternal young age itself. It can be a consequence of other factors including the ethnic, economic, ${ }^{13}$ and family background of mothers, ${ }^{14}$ all of which are not readily amenable to correction by a simple strategy of sex education.

Lord Byron, as renowned as a philanderer as he was a poet, presumably knew whereof he spoke when he wrote in 1819: "The reading or non-reading a book - will never keep down a single petticoat." ${ }^{\prime 15}$

Sex Transm Infect 2002;78:318-319

Authors' affiliations

M Huengsberg, K W Radcliffe, Department of GU Medicine, Whittall Street Clinic,

Birmingham B4 6DH, UK

Correspondence to: Mia Huengsberg mia.huengsberg@bscht.wmids.nhs.uk

\section{REFERENCES}

1 DiCenso A, Guyatt G, Willan A, et al. Intervention to reduce unintended pregnancies among adolescents: systematic review of randomised controlled trials. $B M$

2002;324: 1426-30.

2 Wight D, Raab GM, Henderson M, et al. Limits of teacher delivered sex education: interim behavioural outcomes from randomised trial. BM/ 2002:324:1430-3.

3 Ketting E, Visser AP. Contraception in the Netherlands: the low abortion rate explained. Patient Educ Counc 1994;23:161-71.

4 DiClemente RJ, Wingood GM, Crosby RA, et al. Sexual risk behaviors aoociated with having older sex partners: a study of black adolescent females. Sex Transm Dis 2002;29:20-4.

5 Crosby RA, DiClemente RI, Wingood GM, et al. Correlates of unprotected vaginal sex among African American female adolescents: importance of relationship dynamics. Arch Pediatr Adoles Med 2000;154 893-9.

6 Crosby RA, DiClemente R, Wingood GM, et al. Adolescents' ambivalence about becoming pregnant predicts infrequent contraceptive use: a prospective analysis of nonpregnant African American females. Am J Obstet Gynec 2002; 186:251-2.

7 Epstein JA, Botvin GJ, Fiaz T, et al. Social and personal factors in marijuana use and intentions to use drugs among inner city minority youth. J Develop Behav Pediatr 1995; 16:14-20

8 Epstein JA. Botvin GJ, Diaz T, et al. The role of social factors and individual characteristics in promoting alcohol use among inner-city minority youths. J Stud Alcohol 1995; 56:39-46.

9 Crosby RA, DiClemente R, Wingood GM, et al. HIV/STD prevention benefits of living in supportive families: a prospective analysis of high risk African-American female teens. Am J Health Promotion 2002;16: 142-5.

10 Crosby RA, DiClemente RJ, Wingood GM, et al. Correlates of using dual methods for sexually transmitted diseases and pregnancy prevention among high-risk African-American female teens. J Adoles Health

2001;28:410-4. 
11 Botvin GJ, Baker E, Dusenbury L, et al. Long term follow-up results of a randomized drug abuse prevention trial in a white middle-class population. JAMA 1995;273: $1106-12$.

12 Stevens-Simon C, Lowy R. Teenage childbearing. An adaptive strategy for the socioeconomically disadvantaged or a strategy for adapting to socioeconomic disadvantages? Arch Pediatr Adoles Med 1995;149:912-5

13 Geronimus AT. Black/white differences in the relationship of maternal age to birthweight: a population-based test of the weathering hypothesis. Soc Sci Med 1996;42:589-97.
14 Geronimus AT. Korenman S. Maternal youth or family backgroud? On the health disadvantages of infants with teenage mothers. Am J Epidemiol 1993;137: 213-25.

15 Marchand LA, ed. Byron's letters and journals. Vol 6, 1818-1819. The flesh is frail. London: John Murray, 1976.

\section{Services for sexually transmitted infections in Europe and central Asia}

\section{J S Bingham}

\section{Without adequate surveillance it will not be possible to monitor the situation}

$\mathrm{P}$ hysicians in the affluent, industrialised countries of western Europe probably pay little attention to directives from the World Health Organization (WHO). They investigate and treat their patients as they see fit and they see little attraction, for instance, in the WHO's advocacy of syndromic management for sexually transmitted infections (STIs). ${ }^{1}$ The WHO has a series of policies and principles in relation to STIs which cover prevention, control policies including surveillance and care programmes. ${ }^{2}$ However, knowledge about the state of affairs in relation to STIs is sketchy for most European countries and those of the central Asia republics, all of which come under the Regional Office for Europe in Copenhagen. There, an STI task force has been established to address the situation in eastern Europe and central Asia.

The paper by Dehne et $a l^{\beta}$ in this issue of STI (p 380) is the first survey of these policies across the region. The authors used an adapted WHO model questionnaire which was sent to officials in ministries of health in all 46 countries of Europe and central Asia; 45 replied. This was part of ongoing efforts by the WHO/ UNAIDS to survey the situation in all regions of the world.

\section{COMMENT}

Replies from officials in ministries of health, who are not involved usually at the clinical coalface, may not absolutely reflect the reality on the ground. Overall, however, the replies are likely to be reasonably consistent. The study was conducted in 1998 and it is a pity that there has been such a delay before publication. For instance, some countries now have national management guidelines, such as the United Kingdom, ${ }^{4}$ and the
International Union against Sexually Transmitted Infections (IUSTI) and the WHO have produced model European guidelines. ${ }^{5}$ The United Kingdom also now has a national sexual health strategy.

The newly independent states (NIS) of the former Soviet Union have experienced a spectacular epidemic rise in syphilis, gonorrhoea, and other STIs in recent years, which may now be coming under control. ${ }^{7-11}$ In western Europe, too, there has been a rise in incidence ${ }^{12}$ with trend data showing that the numbers of new diagnoses of sexually acquired HIV infections increased by $20 \%$ between 1995 and $2000 .^{13}$ The situation in some countries of eastern Europe may be worse. $^{14}$

It is against this background that the results of this survey must be viewed. In western Europe much provision of care is at the primary care level and is usually free of charge. Responsibility is largely left to the individual patient and, apart from in the United Kingdom and some Scandinavian countries, there are no national STI control plans or programmes. In about half of the NIS countries, there is some degree of public STI programme. STI services are provided mainly by dedicated clinics, often part of a polyclinic. In some countries, such as the Baltic states, care may be provided privately, ${ }^{35}$ but this type of provision may be more widespread than is realised, particularly when doctors need to supplement a low state salary. While consultation and investigation may be free in these public services, patients in some countries may have to pay for their medication. It seems extraordinary, with outbreaks of syphilis in some Western countries $^{16}$ and the high incidence in the east with people moving extensively around the continent, that Denmark,
Greece, Iceland, and Ireland do not screen donated blood for syphilis and only $75 \%$ of countries routinely screen pregnant women. Drug sensitivity monitoring, particularly for the gonococcus, is not universal.

Few countries have STI services designed to reach specific vulnerable groups. Condoms are freely available in western European countries where their provision may be part of the consultation, but are not so readily available in the east and in central Asia.

Ministry of health officials reported to Dehne et al that all European countries, except Greece, have an STI surveillance system. This may be true but the information provided through these systems is almost certainly a considerable underestimate of the real problem and fairly unreliable because it is difficult to ensure reporting of cases from primary care. On the other hand in the NIS, except in Georgia, STI reporting is universal, most cases being seen in dedicated clinics which are often part of polyclinics. Germany and the Netherlands have virtually abandoned STI surveillance, ${ }^{17}{ }^{18}$ although the Germans feel that sentinel surveillance will be adequate for their needs. While physicians in genitourinary medicine clinics in the United Kingdom are well programmed to produce reliable returns, which are soon to be enhanced, it is unrealistic to expect the non-specialist to do this. Yet without adequate surveillance it will not be possible to monitor the situation. The reality is that, in most countries, the best that is going to be possible is a sentinel system; this will allow capture of data on sexual orientation, ethnic group, and country of origin as well as details of the condition(s) diagnosed. ${ }^{19}$ Nevertheless, ordinary STI surveillance is poor in western Europe, although HIV surveillance is much better.

HIV infection is, in the main, a sexually acquired condition. So it was surprising that in Dehne et al's article it was barely mentioned. With the incidence of this infection increasing across Europe, this is of great concern. Given that other STIs may facilitate HIV transmission $^{20}$ it is obviously of the greatest importance to have adequate, competent services available and, preferably, free of charge. While most patients in western Europe can access free care, in many of the countries of the former Soviet Union, including Russia itself, the consultation may be free but not necessarily the medications required for 
treatment-which may not always be available in some countries. Care of HIV cases is provided in Europe, in the main, by infectious diseases physicians, and management of the traditional STIs often is not a major part of their remit. In Italy, there are some interesting developments by infectious diseases physicians. ${ }^{21}$ In the United Kingdom, it is the STI physicians who provide the bulk of the HIV care, and it is interesting to note that some of the recent outbreaks of syphilis in HIV infected men occurred in areas where this was not the case..$^{22}$ This is illustrative of a certain disconnection of service provision and it does indicate that the potential presence of ordinary STIs should not be overlooked by the non-STI specialist.

There was considerable political interest in the HIV epidemic when it emerged in the 1980s and some HIV prevention programmes were undertaken with a degree of impact, ${ }^{24} 25$ which has probably now been lost. STIs, in general, are not perceived as a major public health priority by many national governments. The fact that in the NIS governments have programmes in place, however rudimentary, is not surprising. These countries have emerged from Soviet rule where the state attempted to supervise every aspect of life. In relation to the control of STIs, a degree of compulsion always existedfor instance, with partner notification. There is no such interference from an overbearing state in western Europe where a state of laissez faire exists. STIs are just not high enough up the medicopolitical agenda and, in some countries, are barely registered on it. Even in the United Kingdom, where the government has been persuaded to produce a national sexual health strategy, its recommendations are to be implemented only in a limited way.

\section{HOPE FOR THE FUTURE}

Despite these comments and Dehn et al's gloomy findings there are some heartening aspects. The overarching specialist body for European dermatovenereologists is the European Academy of Dermatology and Venereology (EADV). At its annual congresses, originally, the STI tracks were very limited but gradually these have been built up with considerable input from the United Kingdom and Ireland, from Germany and from IUSTIEurope. While few European countries have active STI societies/associations, with the reactivation of IUSTI-Europe, regular pan-European meetings are now held and two new national societies have been formed, one in Hungary and another in Estonia. European STI management guidelines have been produced and these can be adapted locally in many of the countries, particularly in western Europe. The guidelines may not be so suitable for central Asia but a US grant giving body is interested in supporting development of guidelines and westernisation of care in that region. ${ }^{26}$ It would be good if these meetings and other IUSTI activities could become a focus for progress in the field in Europe. They could be a forum for discussion about the needs of Europe and its adjacent states, in relation to STIs. Perhaps, using the national societies that do exist and the WHO, it might be possible to move the matter of STIs further up the political agenda across the wider Europe than is presently the $\operatorname{case}^{27}$ and, hopefully, increase the resources available. As Winston Churchill memorably said, when lobbying America for materiel assistance, early in the second world war, "give us the tools and we shall finish the job."

Sex Transm Infect 2002;78:320-321

\section{Author's affiliations}

J S Bingham, Lydia Department, St Thomas's Hospital, Lambeth Palace Road, London SEI 7EH, UK:

james.bingham@gstt.sthames.nhs.uk

\section{REFERENCES}

1 World Health Organization. Guidelines for the management of sexually transmitted infections. WHO/HIV_AIDS/2001.01. Geneva: WHO, 1999.

2 UNAIDS/WHO. Sexually transmitted diseases: policies and principles for prevention and care. UNAIDS/97.6. Geneva: UNAIDS/WHO, 1999.

3 Dehne KL, Riedner G, Neckermann C, et al. A survey of national STI prevention and care policies and programmes in the European region: preliminary results. Sex Transm Infect 2002;78:380-4.

4 Association for Genitourinary Medicine/Medical Society for the Study of Venereal Diseases. Clinical effectiveness guidelines 2002. www.agum.org.uk/ guidelines.htm (accessed 22 July 2002)

5 International Union against Sexually Transmitted Infections-Europe/World Health Organisation. European sexually transmitted infections management guidelines. www.iusti.org/sti/European_Guidelines.pdf (accessed 22 July 2002).

6 Department of Health. The national strategy for sexual health and HIV. London: DoH, 2001
7 Linglof T. Rapid increase of syphilis and gonorrhoea in parts of the former USSR. Sex Transm Dis 1995;22:160-1.

8 Tichonova L, Borisenko K, Ward H, et al. Epidemics of syphilis in the Russian Federation: trends, origins and priorities for control. Lancet 1997;350:210-13.

9 Renton AM, Borisenko KK, Meheus A, et al. Epidemics of syphilis in the newly independent states of the former Soviet Union. Sex Transm Dis 1998;74:165-6.

10 Dehne KL, Prokrovskiy V, Kobyshcha Y, et al. Update on the epidemics of HIV and other sexually transmitted infections in the newly independent states of the former Soviet Union. AIDS 2000;14 (suppl 3):S75-84.

11 Reidner G, Dehne KL, Gomyko A. Recent declines in reported syphilis rates in the former Soviet Union: are the epidemics over? Sex Trans Infect 2000;76:263-5.

12 Adler MW, Meheus AZ. Epidemiology of sexually transmitted infections and human immunodeficiency virus in Europe. JEADV 2000;14:370-7.

13 Nicoll A, Hamers FF. Are trends in HIV, gonorrhoea and syphilis worsening in western Europe? BM 2002;324: 1324-7.

14 World Health Organization Europe STI Task Force. Overview of HIV/AIDS/STI situation in the European Region. www.sti-taskforce.org (accessed 22 July2002).

15 Poder A, Bingham JS. Sexually transmitted infections in Estonia. Int J STD AIDS 1999;10:669-72.

16 Doherty L, Fenton K, Jones J et al. Syphilis: old problem, new strategy. BM 2002;325: 153-6.

17 Petzoldt D, Jappe, Hartmann $M$, et al. Sexually transmitted diseases in Germany. Int J STD AIDS 2002;13:246-53.

18 Coenen AJ, Van der Meijden WI. The organization of STI control in the Netherlands - an overview. Int J STD AIDS 2002;13:254-60.

19 Catchpole MA. The role of epidemiology and surveillance systems in the control of sexually transmitted diseases. Genitourin Med 1996;72:321-9.

20 Fleming DT, Wasserheit JN. From epidemiological synergy to public health policy and practice: the contribution of other sexually transmitted diseases to sexual transmission of HIV infection. Sex Transm Infect 1999;75:3-17.

21 Dal Conte I, Lucchini A, Contuzzi E, et al. Sexually transmitted infections in Italy: an overview. Int J STD AIDS 2001;12:813-18.

22 Higgins SP, Sukthankar A, Mahto M, et al. Syphilis increases in Manchester, UK. Lancet 2000:355: 1466 .

23 Communicable Disease Surveillance Centre. Increased transmission of syphilis in Brighton and Greater Manchester among men who have sex with me. Commun Dis Rep CDR Wkly 2000;10:383-6.

24 Wellings K, Field B. Stopping AIDS. AIDS/HIV public education and mass media in Europe. London: Longman, 1996

25 Nicoll A, Donnelly M, Livingstone S, et al. Assessing the impact of national anti-HIV sexual health campaigns - trends in the transmission of HIV and other sexually transmitted infections in England. Sex Transm Infect $2001 ; 77: 242-7$.

26 Soros Foundation. Personal communication.

27 Bingham JS, Barton SE, Stary A. Sexually transmitted infections and human immunodeficiency virus infection in Europe: the way ahead. JEADV 2001;15:399-401. 